\title{
A Web and SMS Gateway-Based Quality Monitoring Model of Upright Piano Painting
}

\author{
Kasino, Ahmad Juniar, Ridzky Kramanandita \\ Program Studi Sistem Informasi, Sekolah Tinggi Manajemen Industri \\ Jl. Letjen Suprapto no. 26 Cempaka Putih, Jakarta Pusat \\ e-mail: ezz_chocolate@yahoo.com
}

\begin{abstract}
This model of quality monitoring is a web and SMS gateway-based an application which is specifically designed for quality control of upright piano painting in PT XYZ. Previously, the data processing for preparing a daily report consume long time. The painting production always is evaluated every month due to wait collection daily reports for one month. This situation is very to be late and can damage the large number of painting. To overcome this problem, a web and SMS gateway-based quality monitoring model of Upright Piano Painting is designed. This model use evolutionary development algorithm, and based on Unified Modeling Language (UML). The result has indicated that the designed model can speed up the processing of daily data and send a SMS of daily monitoring report of quality upright piano painting to painting manager every day. So the evaluation of the production process can be conducted in daily period instead of monthly.
\end{abstract}

keywords: evolutionary prototype, unified modeling language, quality monitoring application, sms gateway

\begin{abstract}
Abstrak
Quality Monitoring Application adalah sebuah aplikasi yang dirancang untuk pengendalian kualitas upright piano painting di PT XYZ. Pada awalnya, proses pengolahan data harian kualitas painting memerlukan waktu lama untuk menghasilkan sebuah laporan harian. Evaluasi produksi painting selalu dilakukan setelah satu bulan dari akumulasi laporan harian yang menyebabkan banyaknya jumlah kerusakan painting. Oleh karena itu untuk meminimalisasi jumlah kerusakan tersebut, maka dibuatlah sebuah aplikasi dengan menggunakan metode pengembangan sistem evolutionary prototype yang dirancang menggunakan Unified Modeling Language (UML), sehingga menghasilkan aplikasi yang berbasis web dengan SMS gateway. Fungsi aplikasi tersebut adalah untuk mempercepat proses pengolahan data harian dan untuk melakukan monitoring terhadap hasil kualitas upright piano painting dengan mengirimkan SMS kepada manajer painting setiap harinya, sehingga evaluasi terhadap proses produksi dapat dilakukan dalam periode harian.
\end{abstract}

Kata kunci: evolutionary prototype, unified modeling language, quality monitoring application, sms gateway.

\section{Pendahuluan}

Meningkatnya penggunaan teknologi informasi, telah membawa setiap orang dapat melaksanakan berbagai aktivitas dengan lebih akurat, berkualitas dan tepat waktu. Para manajer di berbagai organisasi juga diharapkan dapat dengan lebih mudah untuk menganalisis kinerjanya secara konstan dan konsisten dengan pemanfaatan teknologi informasi dan sistem informasi yang tersedia, salah satunya adalah sistem informasi manajemen [1].

Perkembangan sistem informasi manajemen telah menyebabkan terjadinya perubahan yang cukup signifikan dalam pola pengambilan keputusan yang dilakukan oleh manajemen baik pada tingkat operasional (pelaksana teknis) maupun pimpinan pada semua jenjang. Perkembangan ini juga telah menyebabkan perubahan-perubahan peran dari para manajer dalam pengambilan keputusan, mereka dituntut untuk selalu dapat memperoleh informasi yang paling akurat dan terkini yang dapat digunakannya dalam proses pengambilan keputusan. Salah satu contoh proses pengambilan keputusan yang langsung terhubung dengan konsumen adalah pengambilan keputusan terhadap kualitas produk yang dihasilkan [2-5]. 
Kualitas merupakan salah satu faktor utama bagi konsumen sebelum memutuskan membeli suatu produk. Produk dengan kualitas baik, tahan lama dan handal akan menjadi referensi utama bagi konsumen ketika dia ingin memiliki produk sejenis. Seiring dengan banyaknya konsumen membeli produk tersebut, tanpa disadari brand image perusahaan produsen akan meningkat dan semakin dikenal masyarakat. Sebaliknya, pengalaman konsumen membeli produk dengan kualitas yang mengecewakan dapat menjadi kesan negatif yang sangat tidak menguntungkan bagi pihak perusahaan [6].

PT XYZ merupakan salah satu perusahaan yang bergerak dalam bidang pembuatan dan perakitan alat musik piano. Salah satu jenis piano yang dihasilkan adalah jenis upright piano, yang diproduksi dalam tiga tipe yaitu black/polished ebony, color/polished mahogany dan white/polished white. Dalam melakukan pengendalian kualitas painting terhadap upright piano yang dihasilkan, PT XYZ menetapkan standar persentase maksimal yang diperbolehkan terhadap data kerusakan kualitas upright piano painting yaitu sebesar $10 \%$. Apabila terjadi kerusakan di atas standar yang ditetapkan, maka dilakukan evaluasi dalam periode bulanan terhadap proses painting tersebut.

Data kerusakan kualitas black, color dan white upright piano selanjutnya diolah menjadi laporan total kerusakan upright piano painting dalam periode harian maupun bulanan yang disimpan pada file server perusahaan di dalam folder data kerusakan painting. Laporan tersebut diklasifikasikan berdasarkan tipe upright piano dan jenis kerusakannya dalam bentuk Microsoft Excel. Setiap hari data tersebut dikirim kepada manager painting dalam bentuk email internal perusahaan atau manager painting melihat langsung terhadap data tersebut yang terdapat pada file server, sedangkan untuk laporan bulanan berbentuk hardcopy. Kendala dalam membuat laporan harian tersebut yaitu, update kualitas painting tiap harinya memerlukan waktu sekitar 4 jam.

Lamanya waktu tersebut dapat dipersingkat, apabila terdapat aplikasi yang dapat melakukan upload data kerusakan painting tiap tipe upright piano ke dalam database. Hasil dari pengolahan data tersebut menghasilkan informasi yang ditampilkan dalam bentuk grafik berdasarkan query yang diinputkan oleh manager painting dan laporan otomatis dalam bentuk Portable Document Format (PDF). Selain itu, untuk meminimalisasi kerusakan hasil painting ditambahkan juga fitur SMS gateway yang mengirimkan total kerusakan per hari beserta jenis kerusakan yang terbesar pada hari tersebut, sehingga evaluasi dapat juga dilakukan dalam periode harian

\section{Metodologi}

Quality Monitoring Application adalah aplikasi yang dirancang berbasis web dan SMS gateway dengan tujuan untuk mempercepat proses update data kerusakan kualitas upright piano painting dan untuk memudahkan evaluasi terhadap proses produksi painting tiap harinya.

Pengembangan Quality Monitoring Application terhadap hasil upright piano painting ini menggunakan model prototype jenis evolutionary. Model prototype cocok digunakan untuk menjabarkan kebutuhan user secara lebih detail karena user sering kali kesulitan menyampaikan kebutuhannya secara detail tanpa melihat gambaran yang jelas [7].

Tahapan-tahapan pada model prototype adalah sebagai berikut [7]:

(a) Mengumpulkan kebutuhan pelanggan atau user terhadap perangkat lunak yang akan dibuat.

(b) Membuat prototype agar pelanggan lebih terbayang dengan apa yang sebenarnya diinginkan. Program prototype biasanya merupakan program yang belum jadi.

(c) Program prototype selanjutnya dievaluasi oleh pelanggan atau user sampai ditemukan spesifikasi yang sesuai dengan keinginan pelanggan atau user.

Beberapa tahapan yang dilakukan dalam merancang aplikasi adalah sebagai berikut:

(a) Mengidentifikasi dan menetapkan permasalahan yang terjadi selama penelitian pada sistem monitoring kualitas painting tipe upright piano lama yang terdapat di PT XYZ.

(b) Melakukan studi pendahuluan terlebih dahulu melalui studi literatur. Tujuan melakukan studi literatur adalah untuk mendapatkan landasan teori yang bisa mendukung pemecahan masalah yang sedang diteliti. Teori yang didapatkan merupakan langkah awal agar peneliti dapat lebih memahami permasalahan yang sedang diteliti dengan benar sesuai dengan kerangka berpikir ilmiah. 


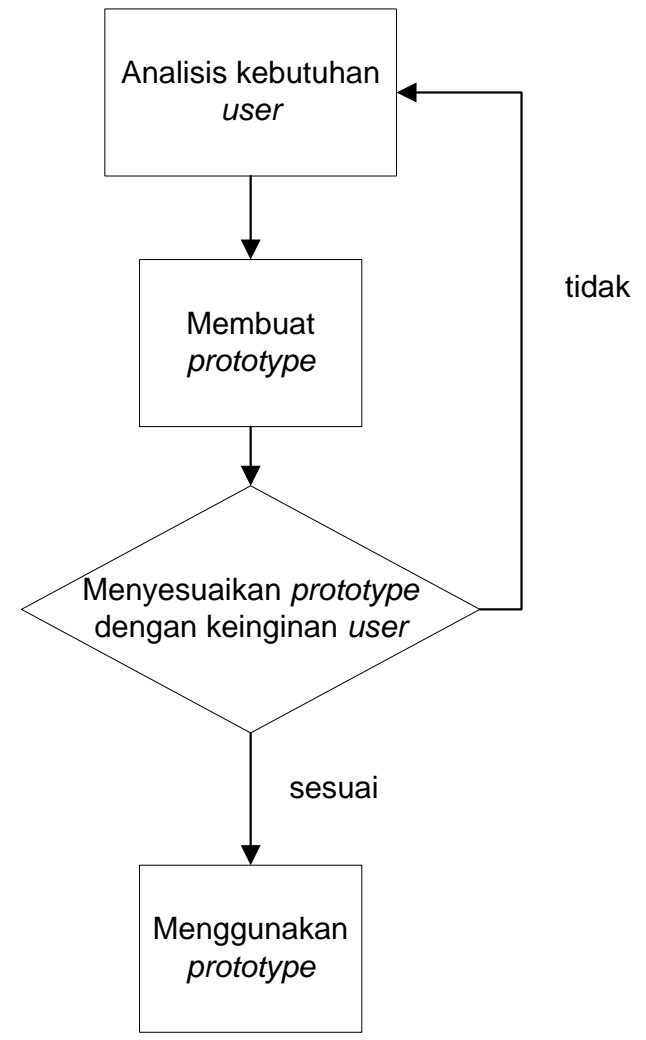

Gambar 1. Evolutionary Prototype Model

(c) Melakukan perumusan masalah dengan menguraikan permasalahan yang dimulai dari permasalahan yang bersifat umum ke masalah yang lebih khusus (spesifik), misalnya:

(d) faktor-faktor apa saja yang membuat kualitas painting sering berada pada kondisi diatas standar minimal yang ditetapkan, walaupun laporan selalu dikirimkan secara rutin?.

(e) Menentukan model desain dan metodologi SDLC yang akan dibuat. Penulis menentukan bahwa desain aplikasi menggunakan UML program. Tujuannya agar UML yang dibuat, hanya menggambarkan fungsi-fungsi yang terdapat pada aplikasi yang diajukan. Untuk metodologi SDLC penulis menggunakan prototype evolusioner.

(f) Mengumpulkan data-data yang diperlukan dengan cara observasi dan wawancara. Data yang dikumpulkan berkaitan dengan kebutuhan user terhadap sistem yang akan dikembangkan, seperti alur dokumen sistem lama yang berjalan, jenis-jenis kerusakan upright piano painting, terminologi upright piano, prosedur dalam melakukan update kualitas upright piano painting dan bentuk informasi yang dihasilkan oleh update data kualitas tersebut.

(g) Melakukan analisis terhadap data yang telah didapat sebelumnya, sehingga dapat diketahui kebutuhan user terhadap aplikasi yang akan dibuat dan juga dapat merancang UML program beserta kamus datanya.

(h) Setelah analisis dilakukan, selanjutnya dari hasil penelitian didapat informasi untuk membuat perancangan database, perancangan interface dan coding aplikasi usulan yang diberi nama Quality Monitoring Application (QMA) yang dibuat dalam bentuk prototype. Pada tahap ini, prototype yang diusulkan akan dilihat apakah sudah sesuai dengan keinginan user atau belum. Jika belum. Maka dilakukan analisis data kembali, tetapi apabila sesuai maka tahap selanjutnya adalah implementasi penggunaan prototype tersebut.

(i) Setelah prototype sistem usulan diterima maka tahap selanjutnya adalah menarik kesimpulan dari penelitian yang telah dilakukan di PT XYZ dan memberikan saran yang membangun bagi perusahaan tersebut. 


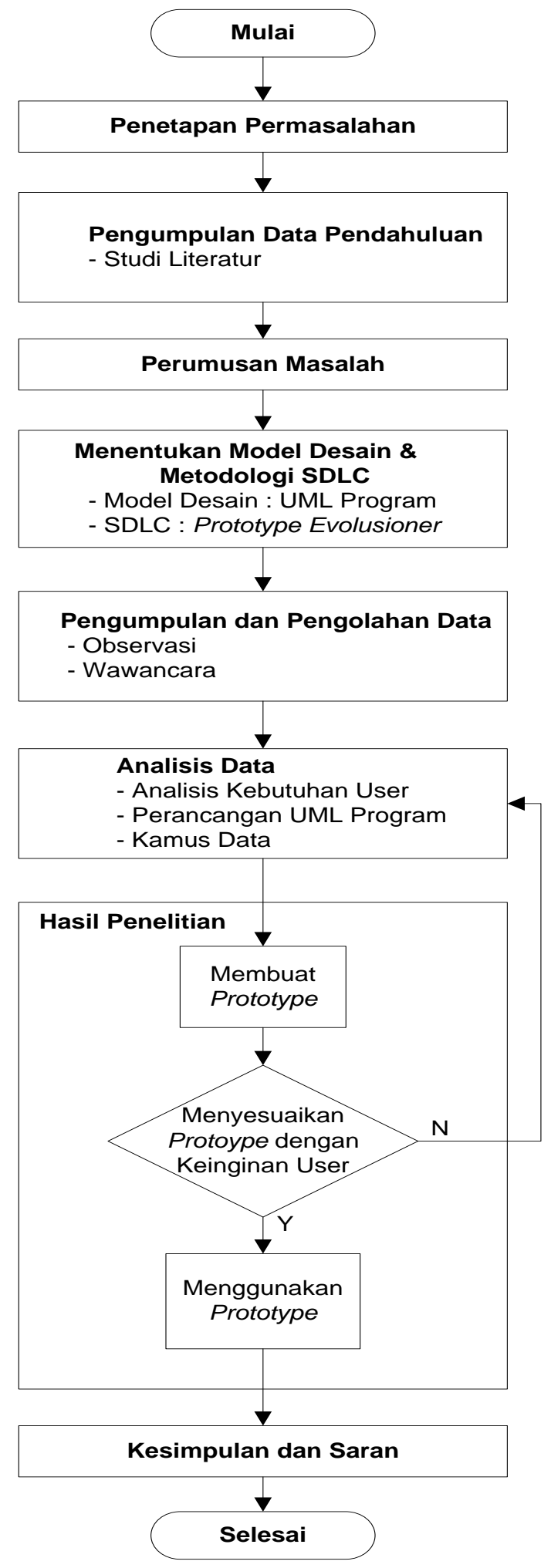

Gambar 2. Flowchart Perancangan Aplikasi

\section{Hasil dan Analisis}

Fase Analisis dilakukan dari observasi dan wawancara kepada karyawan PT XYZ, sehingga menghasilkan perancangan sistem yang baru beserta aplikasi pendukungnya. 


\subsection{Perancangan Arus Dokumen dan Proses}

Perancangan arus dokumen dan proses pada sistem baru bertujuan agar data hasil kerusakan painting dapat dipercepat sehingga laporan kerusakan dapat diterima manajer painting setiap hari via SMS gateway. Perancangan arus dokumen dan proses dapat terlihat pada Gambar 3.

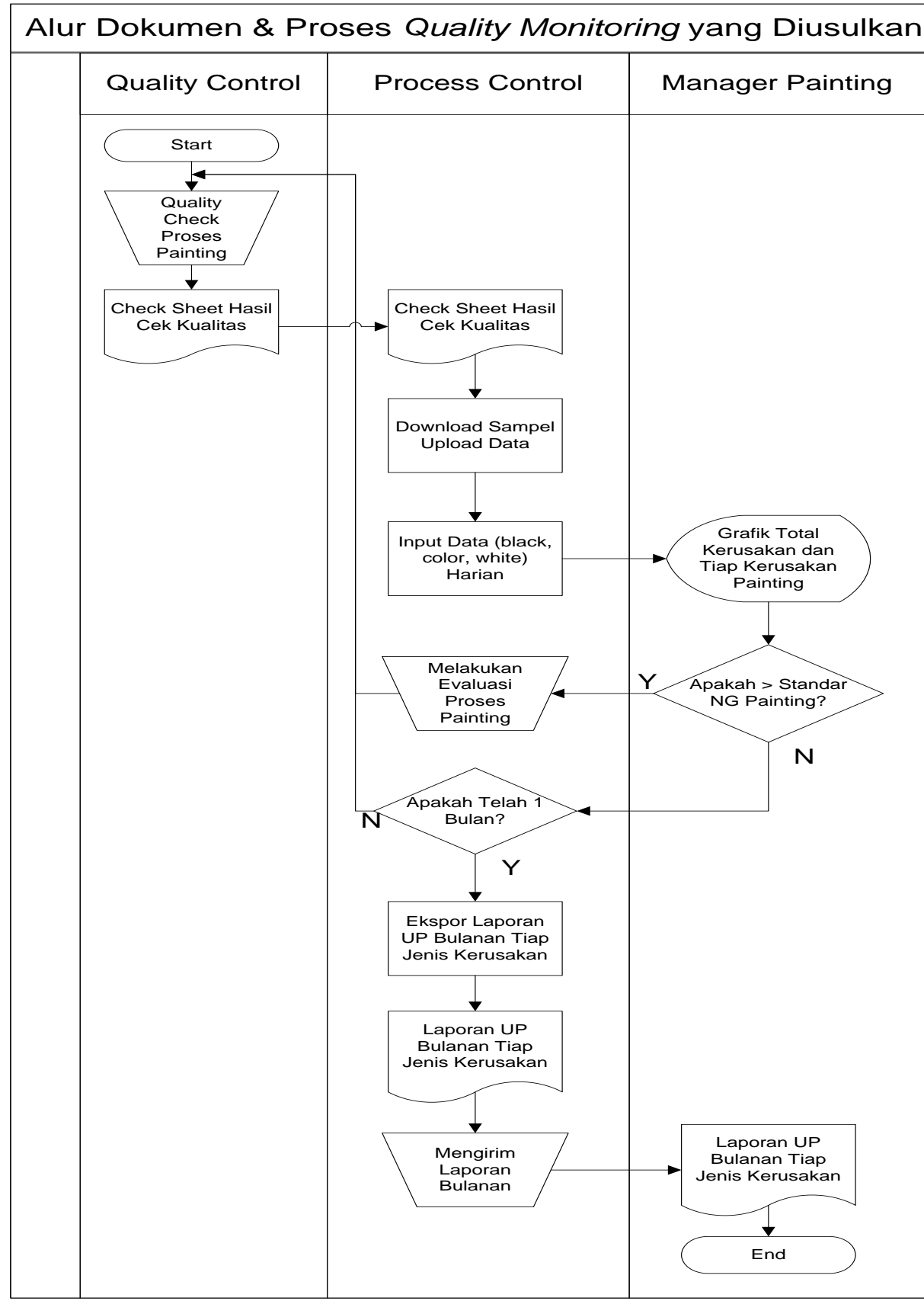

Gambar 3. Perancangan Arus Dokumen dan Proses

\subsection{Perancangan Component Diagram Aplikasi}

Component diagram yang dibuat menggambarkan komponen-komponen yang saling berhubungan pada aplikasi. Untuk perancangan component diagram dapat dilihat pada Gambar 4. 


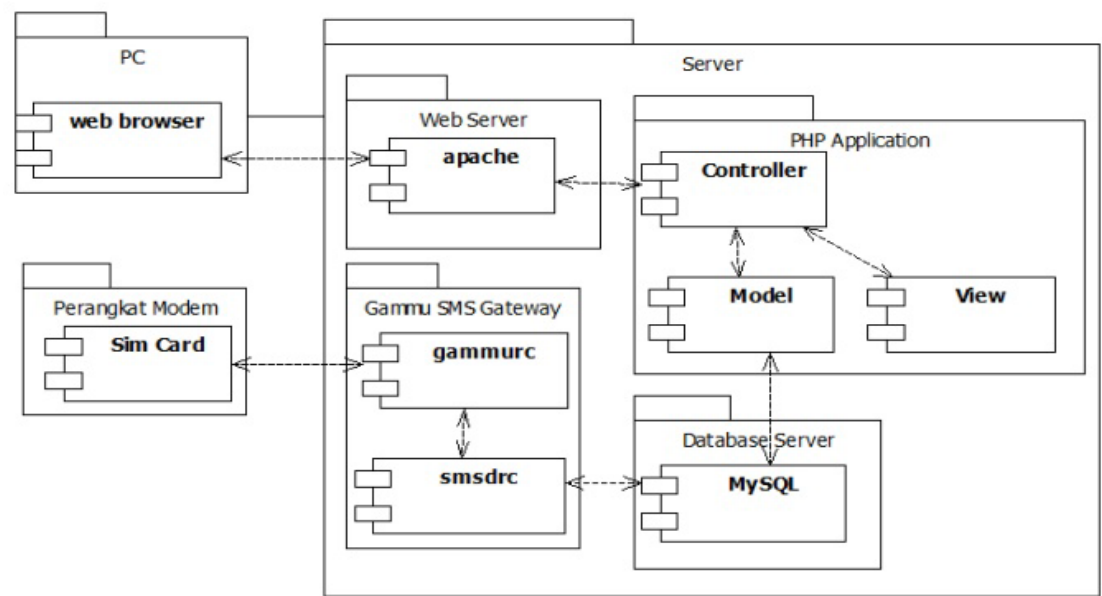

Gambar 4. Perancangan Component Diagram Aplikasi

\subsection{Perancangan Use Case Diagram Aplikasi Usulan}

Use case diagram ini digunakan untuk menjelaskan interaksi antara process control (admin) dan manajer painting (user) dengan rancangan Quality Monitoring Application (QMA). Use case diagram hanya menggambarkan apa yang dapat dilakukan oleh aplikasi dan tidak menggambarkan bagaimana aplikasi melakukannya. Use case diagram rancangan Quality Monitoring Application (QMA) dapat dilihat pada Gambar 5

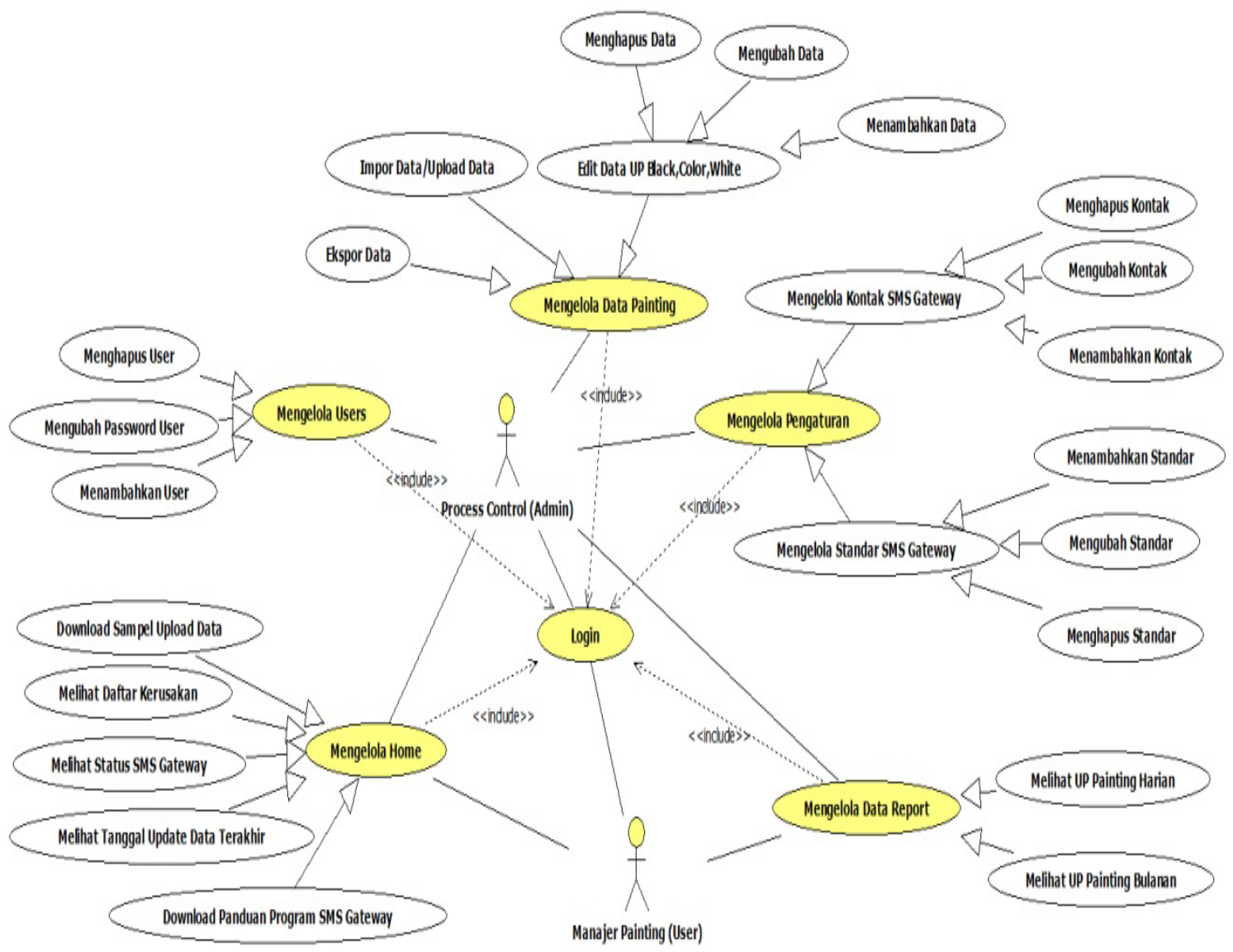

Gambar 5. Perancangan Use Case Aplikasi

JTI Vol. 1, No. 1, September 2013: $48-58$ 


\subsection{Perancangan User Interface Aplikasi}

User interface aplikasi pada setiap modul yang terdapat pada aplikasi adalah sebagai berikut.

(a) Tampilan Beranda/Home Aplikasi

Hasil Perancangan Beranda/Home Aplikasi ditunjukkan pada Gambar 6.
QMA
Home Users
Data Painting
Data Report
Pengaturan
Selamat Datang, admin I Logout

JENIS UPRIGHT PIANO YANG DIPRODUKSI
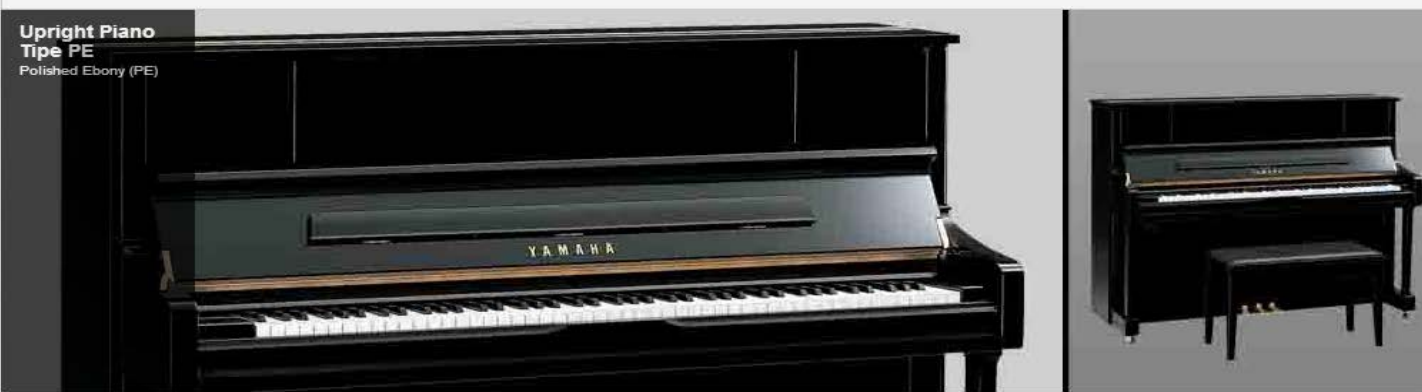

SELAMAT DATANG

Status SMS Gateway

Status Pengaturan Standar Minimal UP Right All Models :

Tanggal Update Terakhir

Daftar Kerusakan

Panduan Program Ini

Catatan. Selalu periksa

inputan standar minima

Pegaturan->Standar SMS

Gateway) yang ditetapkan

agar kualitas painting selalu

terjaga.

웅

Kasino | Sekolah Tinggi Manajemen Industri | Program Studi Sistem Informasi | Hak Cipta e2012 KZ Desian | powered by Adminus Template v1.

Gambar 6. Perancangan Beranda/Home Aplikasi

(b) Tampilan Beranda/Home Aplikasi

QMA Home Users Data Painting Data Report Pengaturan Selamat Datang, admin I Logout

DAFTAR USER

\begin{tabular}{|l|l|}
\hline No & Username \\
\hline 1 & admin \\
\hline 2 & kasino \\
\hline 3 & nano \\
\hline
\end{tabular}

응
Standar Nimimal UP Right All Models TELAH di setting! Import data dapat digunakan!

(8)

Status Daftar Kontak Nomer Handphone :

Nomer Handphone Tujuan SMS Gateway TELAH di setting! Import data dapat digunakan!

Kasino | Sekolah Tinggi Manajemen Industri | Program Studi Sistem Informasi | Hak Cipta @2012 KZ Desian | powered by Adminus Template v1.4

Gambar 7. Perancangan Tampilan Menu Users 
(c) Tampilan Laporan Painting Harian Total Kerusakan

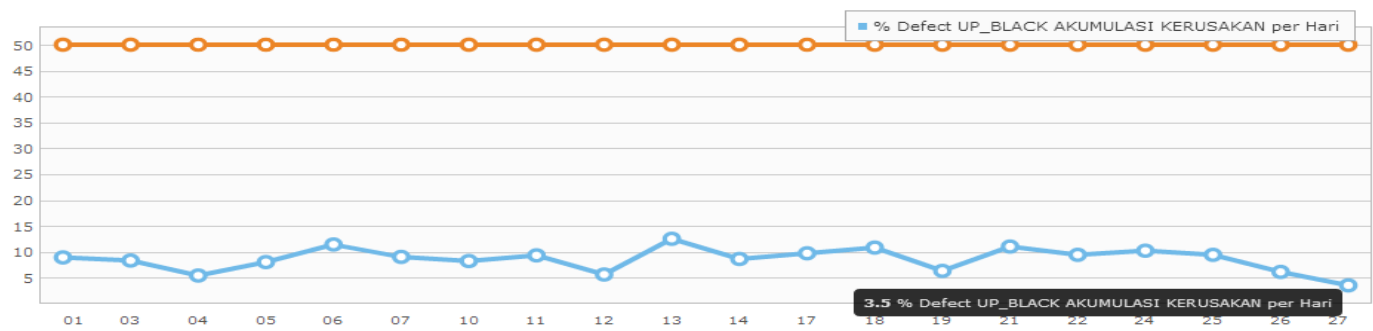

Gambar 8. Perancangan Tampilan Laporan Painting Harian Total Kerusakan

(d) Tampilan Laporan Painting Harian Tiap Kerusakan

BULAN SEPTEMBER TAHUN 2012 / PAINTING : UP_BLACK / JENIS CACAT : MUKE_PERMUKAAN

\begin{tabular}{|c|c|c|c|c|c|c|c|c|c|c|c|c|c|c|c|c|c|c|c|c|}
\hline Nama Cabinet & 01 & 03 & 04 & 05 & 06 & 07 & 10 & 11 & 12 & 13 & 14 & 17 & 18 & 19 & 21 & 22 & 24 & 25 & 26 & 27 \\
\hline Side Arm & 0 & 0 & 1 & 1 & 2 & 0 & 1 & 1 & 0 & 2 & 0 & 0 & 1 & 0 & 1 & 3 & 2 & 0 & 0 & 0 \\
\hline Side Board & 4 & 0 & 3 & 6 & 0 & 1 & 0 & 0 & 4 & 0 & 3 & 9 & 6 & 5 & 5 & 3 & 2 & 4 & 3 & 0 \\
\hline Side Sleeve & 2 & 0 & 1 & 0 & 0 & 0 & 2 & 1 & 1 & 0 & 0 & 1 & 0 & 0 & 0 & 0 & 3 & 2 & 0 & 0 \\
\hline Side Base & 5 & 0 & 5 & 6 & 3 & 3 & 2 & 2 & 4 & 7 & 0 & 0 & 0 & 3 & 2 & 2 & 5 & 7 & 0 & 0 \\
\hline Leg & 0 & 0 & 0 & 1 & 1 & 0 & 1 & 2 & 0 & 0 & 0 & 0 & 0 & 1 & 0 & 0 & 0 & 1 & 0 & 0 \\
\hline Top Board & 1 & 2 & 9 & 9 & 6 & 3 & 2 & 4 & 5 & 6 & 5 & 5 & 5 & 2 & 2 & 4 & 0 & 6 & 3 & 0 \\
\hline Top Board Front & 0 & 3 & 1 & 2 & 0 & 0 & 0 & 2 & 0 & 2 & 1 & 2 & 2 & 2 & 0 & 1 & 0 & 0 & 1 & 0 \\
\hline Top Board Rear & 0 & 0 & 3 & 0 & 0 & 0 & 0 & 0 & 1 & 1 & 2 & 0 & 0 & 0 & 0 & 0 & 1 & 0 & 0 & 0 \\
\hline Top Frame (C) & 1 & 0 & 0 & 0 & 0 & 6 & 0 & 0 & 0 & 2 & 1 & 0 & 1 & 0 & 2 & 0 & 2 & 2 & 3 & 0 \\
\hline Top Frame ( R/L ) & 0 & 0 & 0 & 0 & 0 & 0 & 0 & 0 & 0 & 0 & 0 & 0 & 0 & 0 & 0 & 0 & 0 & 0 & 0 & 0 \\
\hline Top Frame Side ( R/L ) & 0 & 1 & 0 & 0 & 0 & 0 & 0 & 6 & 0 & 0 & 0 & 0 & 0 & 0 & 0 & 0 & 1 & 1 & 0 & 0 \\
\hline Fall Back U1J & 1 & 1 & 1 & 0 & 0 & 0 & 0 & 0 & 0 & 0 & 0 & 0 & 5 & 0 & 2 & 0 & 2 & 1 & 2 & 0 \\
\hline Fall Back b1 \& b2 & 5 & 3 & $\mathbf{1}$ & 7 & 0 & 5 & 2 & 3 & 1 & 1 & 2 & 3 & 0 & 0 & 1 & 6 & 6 & 1 & 0 & 0 \\
\hline Fall Center & 3 & 13 & 7 & 2 & 7 & 7 & 3 & 8 & 2 & 4 & 3 & 3 & 2 & 3 & 4 & 9 & 0 & 3 & 6 & 1 \\
\hline Fall Board & 0 & 0 & 0 & 0 & 0 & 0 & 0 & 0 & 0 & 0 & 0 & 0 & 0 & 0 & 0 & 0 & 0 & 0 & 0 & 0 \\
\hline Fall Front & 1 & 2 & 2 & 1 & 0 & 1 & 0 & 2 & 0 & 2 & 1 & 5 & 4 & 0 & 0 & 0 & 4 & 0 & 0 & 1 \\
\hline Hinge Strip & 7 & 0 & 0 & 1 & 3 & 1 & 1 & 6 & 0 & 5 & 0 & 9 & 4 & 1 & 2 & 4 & 5 & 0 & 1 & 0 \\
\hline Key Slip & 0 & 2 & 2 & 0 & 1 & 2 & 0 & 0 & 0 & 2 & 2 & 2 & 0 & 0 & 0 & 2 & 1 & 0 & 0 & 1 \\
\hline Key Bed & 0 & 0 & 0 & 0 & 0 & 0 & 0 & 1 & 0 & 0 & 0 & 0 & 0 & 0 & 0 & 0 & 0 & 0 & 0 & 0 \\
\hline Key Block & 1 & 1 & 0 & 0 & 2 & 0 & 1 & 0 & 0 & 2 & 0 & 0 & 5 & 1 & 0 & 0 & 4 & 0 & 0 & 0 \\
\hline Bottom Frame & 1 & 0 & 1 & 1 & 0 & 0 & 0 & 0 & 0 & 0 & 0 & 0 & 0 & 0 & 0 & 0 & 0 & 0 & 0 & 1 \\
\hline Pedal Rail & 0 & 0 & 0 & 0 & 1 & 2 & 0 & 0 & 0 & 0 & 0 & 0 & 0 & 0 & 0 & 0 & 0 & 0 & 0 & 0 \\
\hline Music Desk & 0 & 0 & 0 & 0 & 0 & 0 & 0 & 0 & 0 & 0 & 0 & 0 & 0 & 0 & 0 & 0 & 0 & 0 & 0 & 0 \\
\hline Top Frame Sill & 0 & 0 & 0 & 0 & 0 & 0 & 0 & 0 & 0 & 0 & 0 & 0 & 0 & 0 & 0 & 0 & 0 & 0 & 0 & $\mathbf{1}$ \\
\hline JUMLAH & 32 & 28 & 37 & 37 & 26 & 31 & 15 & 38 & 18 & 36 & 20 & 39 & 35 & 18 & 21 & 34 & 38 & 28 & 19 & 5 \\
\hline
\end{tabular}

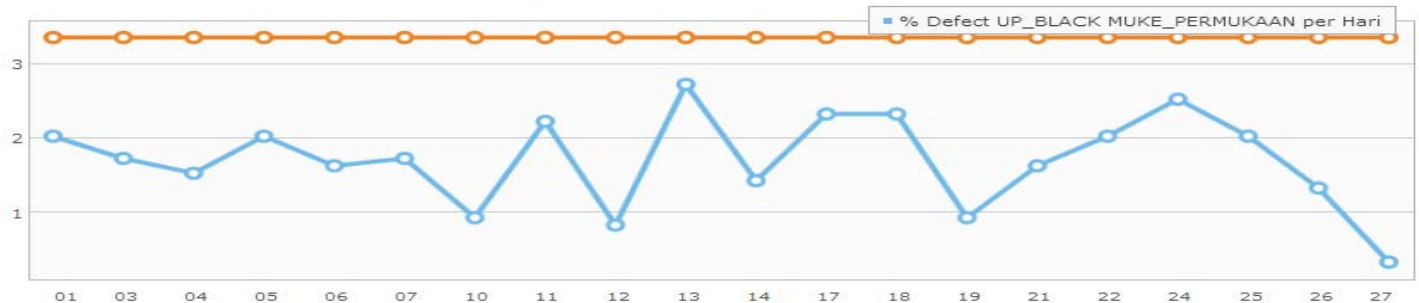

Gambar 9. Perancangan Tampilan Laporan Painting Harian Tiap Kerusakan 
(e) Tampilan Laporan Painting Bulanan Total Kerusakan

\section{PERBANDINGAN TOTAL KERUSAKAN PER BULAN TAHUN 2012 / PAINTING : UP_BLACK}

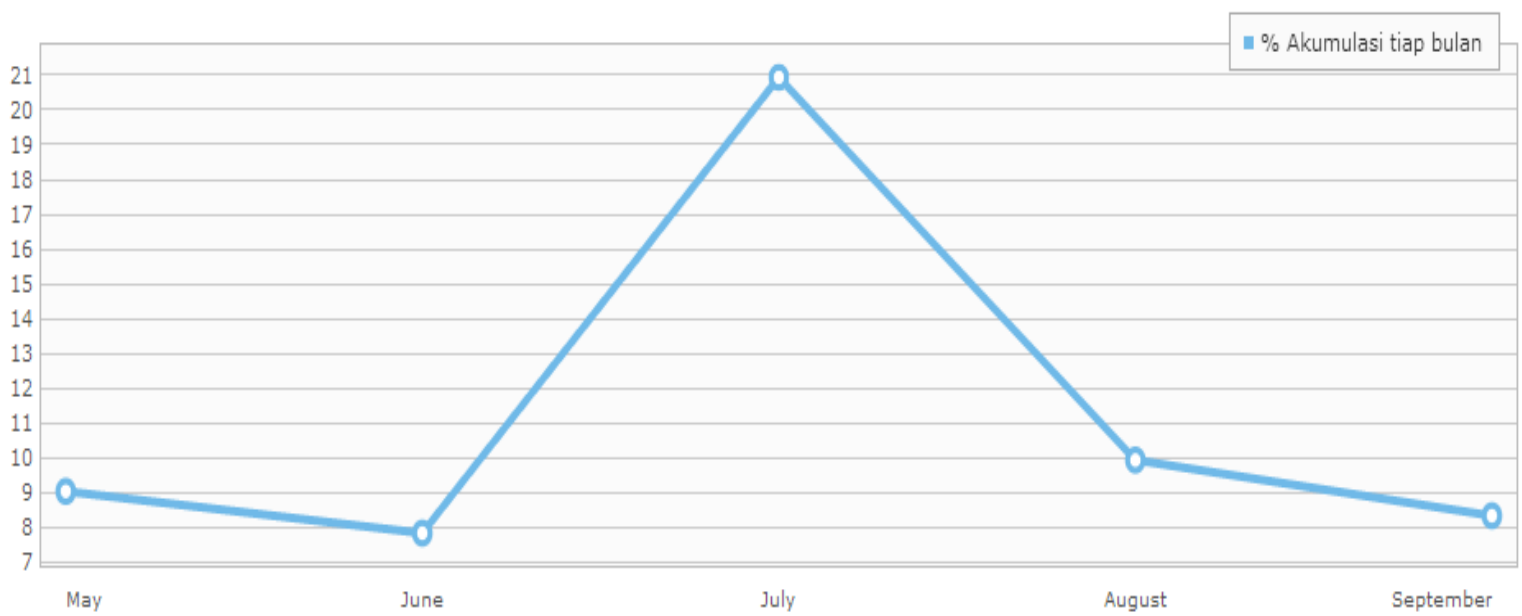

Gambar 10. Perancangan Tampilan Laporan Painting Bulanan Total Kerusakan

\subsection{Perancangan Tampilan Pesan SMS Gateway} berikut.

User interface aplikasi pada setiap modul yang terdapat pada aplikasi adalah sebagai

(a) Pengiriman Otomatis Melalui SMS Gateway

Tampilan apabila terjadi kerusakan di atas standar maksimal kerusakan yang ditetapkan maka SMS gateway akan mengirimkan SMS kepada nomor yang telah terdaftar, seperti Gambar 11.

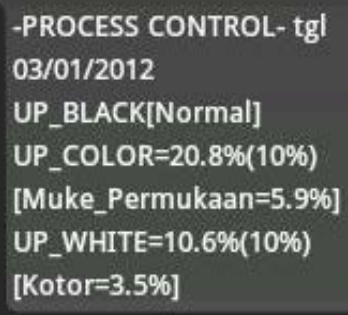

Gambar 11. Tampilan SMS Gateway Setelah Proses Input Data

Penjelasan pesan SMS gateway yaitu 'UP_COLOR' mewakili tipe dari piano, untuk '20.8\%' mewakili total kerusakan harian pada jenis piano tersebut, untuk angka '10\%' yang berada di dalam tanda kurung mewakili standar maksimal kerusakan, untuk 'Muke_Permukaan' dan '5.9\%' mewakili jenis kerusakan yang terbesar dan total persentase pada tanggal tersebut.

(b) Pengiriman Informasi Melalui SMS Gateway Apabila nomor handphone telah didaftarkan, maka dapat meminta informasi melalui SMS dengan mengetik kepada nomor SMS Gateway:

[UP][spasi][dd/mm/yyyy] contoh: UP 03/04/2012

Maka aplikasi akan membalas salah satu pesan pada Gambar 12. 


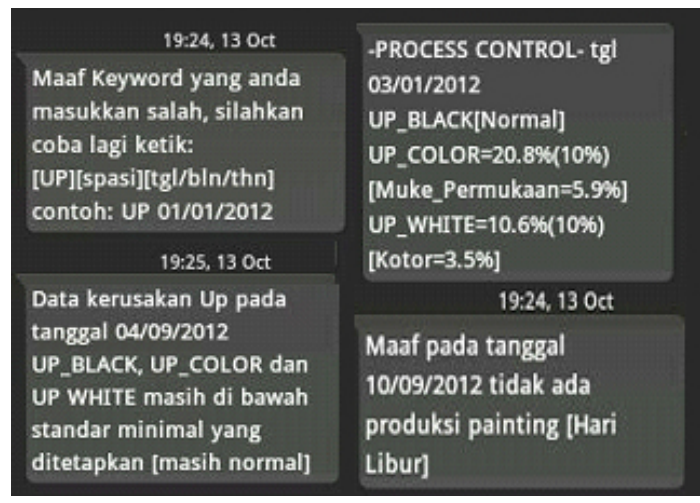

Gambar 12. Tampilan Pesan Permintaan Informasi Melalui SMS Gateway

\section{Simpulan}

Berdasarkan hasil pengumpulan, pengolahan dan analisis data yang telah dilakukan dalam penelitian ini dapat disimpulkan bahwa:

(a) Dengan adanya Quality Monitoring Application dapat mempercepat waktu update data kerusakan painting menjadi 10 menit dari sebelumnya selama 4 jam.

(b) Tampilan grafik lebih user friendly dan mudah digunakan, karena hanya melakukan query pada combobox.

(c) Lebih mudah dalam menganalisis kerusakan tiap model upright piano per bulan

(d) Lebih mudah dalam membuat laporan tiap kerusakan dalam periode harian pada semua model upright piano.

(e) Kerusakan painting dapat ditekan seminimal mungkin, karena kualitas painting selalu dipantau setiap hari melalui SMS gateway.

\section{Referensi}

[1] Jaluanto, Widyaningrum D. Analisis Kualitas Produk, Biaya Kualitas dan Volume Penjualan. Serat Acitya. 2012; 1(1): 1-10.

[2] Hermawan B. Pengaruh Kualitas Produk Terhadap Kepuasan, Reputasi Merek dan Loyalitas Konsumen Jamu Tolak Angin PT Sido Muncul. Jurnal Manajemen Teori dan Terapan. 2011; 4(2): 917.

[3] Mcleod R. Sistem Informasi Manajemen. Jakarta: PT Indeks. 2004.

[4] Ariani W. Manajemen Kualitas. Yogyakarta: Universitas Atma Jaya. 1999.

[5] Chung W, Wong M, Soon. An Ann-Based Dss System for Quality Assurance in Production Network. Journal of Manufacturing Technology Management. 2007; 18(7): 836-857.

[6] Jogiyanto. Analisis dan Desain Sistem Informasi: Pendekatan Terstruktur Teori dan Praktik Aplikasi Bisnis. Yogyakarta: Andi. 2001.

[7] Rosa AS, Shalahuddin M. Rekayasa Perangkat Lunak (Terstruktur dan Berorientasi Objek). Bandung: Modula. 2011.

[8] Wiharto Y. Sistem Informasi Akademik Berbasis SMS Gateway. Jurnal Teknologi dan Informatika (TEKNOMATIKA). 2011; 1(1): 1-28.

[9] Pertiwi D. Desain dan Implementasi Sistem Informasi Perpustakaan Berbasis Web dengan MVC (Model, View, Controller). Jurnal Teknologi dan Informatika (TEKNOMATIKA). 2011; 1(2): 125-147. 
